\title{
Atrial Fibrillation Ablation - Benefits Beyond Symptom Reduction with a Focus on Patients with Heart Failure with Reduced Ejection Fraction
}

\author{
Norbert Guettler, ${ }^{1,2}$ Kim Rajappan ${ }^{3}$ and Edward Nicol ${ }^{4}$ \\ 1. Internal Medicine and Cardiology, Air Force Centre of Aerospace Medicine, Fuerstenfeldbruck, Germany; 2. Central Military Hospital, \\ Koblenz, Germany; 3. Cardiac Department, John Radcliffe Hospital, Oxford University Hospitals NHS Foundation Trust, Oxford, UK; \\ 4. Department of Cardiology, Royal Brompton Hospital, London, UK
}

\section{Keywords}

Atrial fibrillation, catheter ablation, prognostic benefits, heart failure with reduced ejection fraction

Disclosures: Norbert Guettler, Kim Rajappan and Edward Nicol have nothing to disclose in relation to this article.

Review Process: Double-blind peer review.

Compliance with Ethics: This study involves a review of the literature and did not involve any studies with human or animal subjects performed by any of the authors.

Authorship: The named authors meet the International Committee of Medical Journal Editors (ICMJE) criteria for authorship of this manuscript, take responsibility for the integrity of the work as a whole, and have given final approval for the version to be published.

Received: 7 April 2019

Accepted: 29 May 2019

Citation: European Journal of Arrhythmia

\& Electrophysiology. 2019;5(1):30-8

Corresponding Author: Norbert Guettler, Air Force Centre of Aerospace Medicine, Strasse der Luftwaffe 322, 82256 Fuerstenfeldbruck, Germany. E: guettlern@aol.com

Support: No funding was received for the publication of this article.
Catheter ablation for atrial fibrillation (AF) is now a widely established treatment to prevent AF recurrence. Catheter ablation usually involves the isolation of the pulmonary veins, which is an adequate strategy in the majority of cases with paroxysmal AF. Persistent AF, however, often requires additional substrate modification. ${ }^{1-3}$ Several strategies of substrate modification are under evaluation. While complex fractionated atrial electrograms and linear lesions have been abandoned as a consequence of the STAR AF II (Substrate and Trigger Ablation for Reduction of Atrial Fibrillation Trial-Part II) results, ${ }^{4}$ the ablation of fibrotic areas, posterior wall isolation, and the ablation of non-pulmonary vein triggers show more promising results. The ablation results of rotational activity are still contradictory. ${ }^{3}$ In many clinical trials, catheter ablation has proven superior over antiarrhythmic drug therapy for the maintenance of sinus rhythm and the improvement of quality of life. ${ }^{5-7}$ In the latest guidelines for the management of $A F$, the European Society of Cardiology recommends catheter ablation in patients with symptomatic recurrences of AF on antiarrhythmic drug therapy for paroxysmal AF (class I, level of evidence A), and persistent AF (class Ila, level of evidence C). ${ }^{8}$ In selected patients it should be considered as a first-line therapy to prevent recurrent AF to improve symptoms as an alternative to antiarrhythmic drug therapy, considering patient choice, benefit, and risk (class Ila, level of evidence B recommendation). Similar recommendations are given by the American Heart Association (AHA), the American College of Cardiology (ACC), and the Heart Rhythm Society (HRS) in their 2014 guidelines. ${ }^{9}$

Beyond improvement of symptoms and quality of life, several recent studies have demonstrated the prognostic benefit of catheter ablation for certain patient groups including reduced mortality and a reduction in hospitalisation. As a result of these trials, AHA, ACC and HRS added the recommendation in their 2019 focused update (of the 2014 guideline) that AF catheter ablation may be reasonable in selected patients with symptomatic AF and heart failure with reduced ejection fraction (HFrEF), to potentially lower mortality rates and reduce hospitalisation for heart failure (HF). ${ }^{10}$

In this article, recent clinical trials, meta-analyses, and reviews will be analysed to address whether catheter ablation for AF can have a prognostic benefit beyond symptom reduction in patients with HF. Different results for variable patient groups will be highlighted. 


\section{Clinical trials}

A number of clinical trials have tried to answer the question of whether AF ablation can demonstrate prognostic benefit beyond symptom reduction and improvement of quality of life. There have been several publications reporting favourable effects of catheter ablation on death, stroke, dementia and other outcomes in patients with AF in general. ${ }^{11,12}$ An emerging number of clinical trials have analysed the effects of AF ablation in patients with HFrEF, while data concerning AF ablation in patients with heart failure with mid-range (HFmrEF) and preserved ejection fraction (HFpEF) is much sparser. ${ }^{13}$

\section{Catheter ablation of atrial fibrillation in patients not restricted to those with heart failure}

Several trials on the outcome of catheter ablation for AF have been published including the general population with AF not restricted to HF.

\section{RAAFT-1}

The RAAFT-1 (Radiofrequency Ablation vs Antiarrhythmic Drugs as First-line Treatment of Symptomatic Atrial Fibrillation) trial was published in 2005 to determine whether pulmonary vein isolation (PVI) is feasible as first-line therapy for treating patients with symptomatic AF. ${ }^{14}$ Patients were randomised to receive either PVI using radiofrequency energy $(n=33)$ or antiarrhythmic drug treatment $(n=37)$ with a 1-year follow-up. At the end of the follow-up period the results were significantly better in the PVI group. AF recurrences were lower $(p<0.001)$, there were fewer hospitalisations $(p<0.001)$, and quality of life was significantly better in the PVI group. The authors concluded that PVI appeared to be a feasible first-line approach for treating patients with symptomatic AF.

\section{RAAFT-2}

The RAAFT-2 (Radiofrequency Ablation vs Antiarrhythmic Drugs as First-line Treatment of Paroxysmal Atrial Fibrillation) compared radiofrequency ablation with antiarrhythmic drugs (standard therapy) in treating patients with paroxysmal AF as a first-line therapy. ${ }^{15} \mathrm{~A}$ total of 127 patients were enrolled; 61 were randomised to the antiarrhythmic drug group, 66 to the radiofrequency ablation group with a follow-up of 24 months each. The primary endpoint was the first documented atrial tachyarrhythmia of more than 30 seconds. Secondary endpoints included symptomatic recurrences of atrial tachyarrhythmia and quality of life. Forty-four patients (72.1\%) in the antiarrhythmic drug group and 36 patients $(54.5 \%)$ in the ablation group experienced the primary efficacy outcome (hazard ratio [HR] 0.56; 95\% confidence interval [Cl] $0.35-0.90 ; p=0.02$ ). Among patients with paroxysmal AF without previous antiarrhythmic drug treatment, radiofrequency ablation resulted in a lower rate of recurrent atrial tachyarrhythmias at 2 years when compared with antiarrhythmic drugs. However, recurrence was frequent in both groups.

\section{MANTRA-PAF}

The MANTRA-PAF (Radiofrequency Ablation as Initial Therapy in Paroxysmal Atrial Fibrillation) trial compared radiofrequency ablation with antiarrhythmic drug therapy as first-line treatment in patients with paroxysmal $\mathrm{AF}^{16} \mathrm{~A}$ total of 294 patients without previous antiarrhythmic drug treatment were randomised to either radiofrequency ablation ( $n=146)$ or antiarrhythmic drug treatment $(n=148)$. The authors found no significant difference between both groups in the cumulative burden of AF over a period of 2 years.

\section{CABANA}

The goal of the CABANA (Catheter Ablation versus Antiarrhythmic Drug Therapy for Atrial Fibrillation) trial was to compare the safety and efficacy of catheter ablation compared with drug therapy for the treatment of patients with new-onset or untreated $A F^{17,18} A$ total of 2,204 patients were randomised 1:1 for either catheter ablation $(n=1,108)$ or drug therapy $(n=1,096)$. Primary ablation was performed with standard techniques (PVI/wide area circumferential ablation). Ancillary ablation was added as needed. Drug therapy could be either for rate or rhythm control. The study details are listed in Table 1.

The full manuscript of the CABANA trial has not yet been published. So far, the results indicate that ablation is not superior to drug therapy for cardiovascular outcomes at 5 years among patients with new-onset or untreated AF requiring therapy, as the primary endpoint was missed in the intention-to-treat analysis. However, analysing secondary endpoints there was a significant reduction in death or cardiovascular hospitalisation with ablation, and a significant reduction in AF recurrence. The study also showed that ablation is a safe procedure, as the rate of adverse events was low. The main controversy, however, is caused by the fact that some electrophysiologists, including the principal investigator of this study, point to the positive results of a per protocol, or as-treated, analysis regarding the primary endpoint. They argue that the crossover rate in the study was comparatively high and that $27.5 \%$ of patients randomised to drug therapy were finally ablated, while $9.2 \%$ of patients randomised to the ablation arm did not undergo ablation.

Data for the primary endpoint based on treatment received in a per protocol analysis for ablation versus drug therapy showed a significant advantage for the ablation group with regard to all-cause mortality, death or cardiovascular hospitalisation. These findings may be considered hypothesis generating for further studies.

One of the caveats in this study is that the drug arm is quite heterogeneous, and it remains unclear if drug therapy for rhythm control would have been superior to a rate control strategy. Additionally, the trial is only single-blind. It is not blinded to the intervention received.

\section{CAPTAF}

The recently published CATPAF (Effect of Catheter Ablation vs Antiarrhythmic Medication on Quality of Life in Patients with Atrial Fibrillation) trial assessed quality of life with catheter ablation versus antiarrhythmic medication at 12 months in patients with AF. ${ }^{19} \mathrm{~A}$ total of 155 patients aged 30-70 years with more than 6 months of AF and treatment failure with one antiarrhythmic drug or beta-blocker were enrolled in the study. They were randomised to catheter ablation $(n=79)$ or previously untested antiarrhythmic drugs $(n=76)$, with 4-year follow-up. The primary outcome was the General Health subscale score (Medical Outcomes Study 36-Item Short-Form Health Survey) at baseline and 12 months, assessed unblended. Among patients with symptomatic AF despite use of antiarrhythmic medication, the improvement in quality of life at 12 months was greater for those treated with catheter ablation compared with antiarrhythmic medication. Although the study was limited by absence of blinding, catheter ablation may offer an advantage for quality of life.

\section{Catheter ablation of atrial fibrillation in patients with heart failure with reduced ejection fraction} There have been several observational studies evaluating the effect of catheter ablation for AF on left ventricular ejection fraction (LVEF) in patients with $\mathrm{HF}^{20-39}$ The median improvement of LVEF in the ablation group was $13 \%$. In the nine studies consisting of patients with normal ejection fraction as a comparator arm, ${ }^{20-23,26,27,31,3,3,39}$ the median improvement of LVEF was $12 \%$. 
Table 1: Study details of the CABANA trial

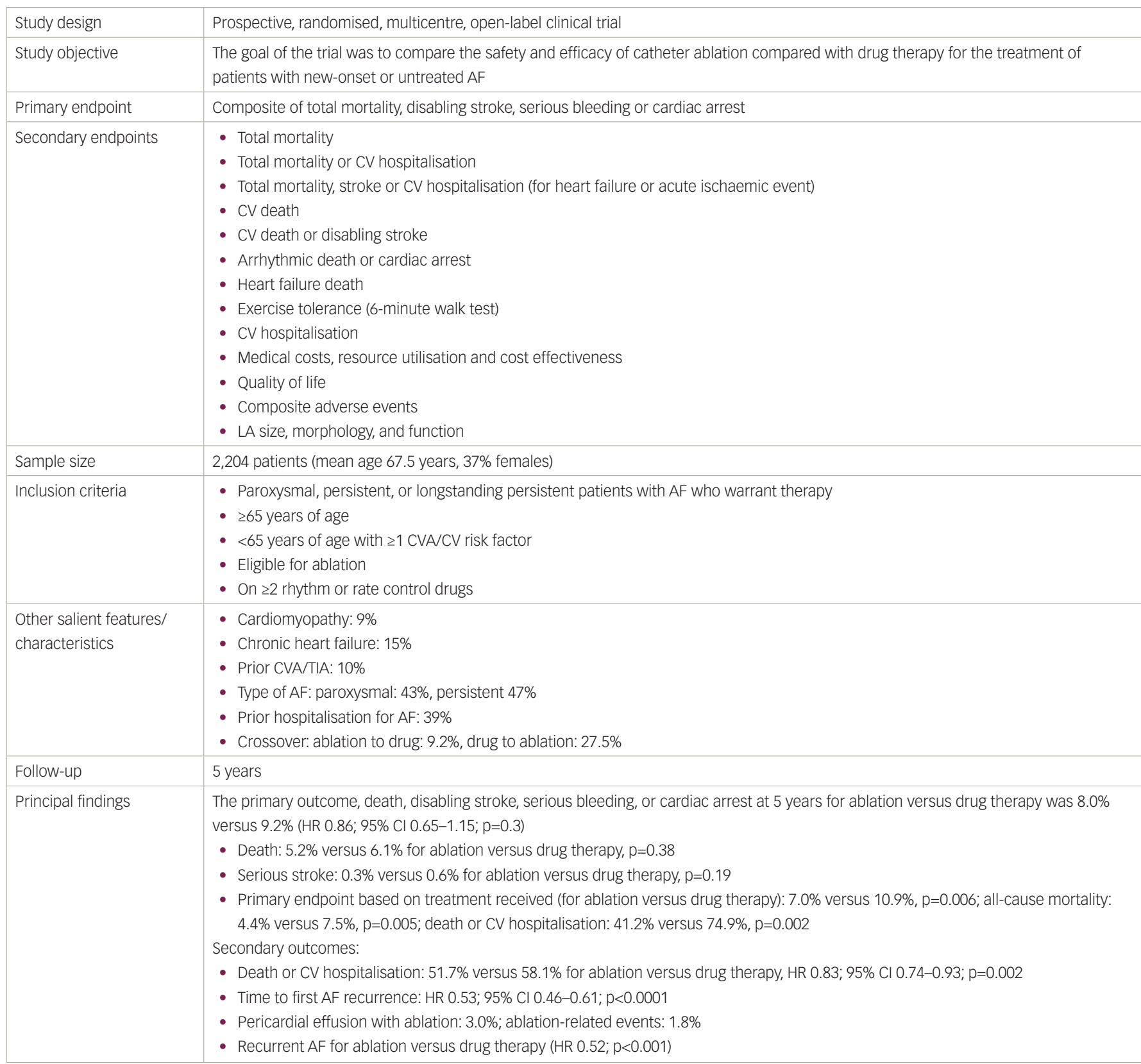

$A F=$ atrial fibrillation; $C A B A N A=$ Catheter Ablation versus Antiarrhythmic Drug Therapy for Atrial Fibrillation; $C l=$ confidence interval; $C V=$ cardiovascular; $C V A=$ cerebrovascular accident; $H R=$ hazard ratio; $L A=$ left atrium; TIA = transient ischaemic attack.

The seven randomised controlled trials ${ }^{40-46}$ evaluating prognostic benefits of AF ablation in HFrEF patients are described in the following sections and summarised in Table 2. The most recently published of these randomised controlled trials, and potentially impactful, is the CASTLE-AF trial.

\section{CASTLE-AF}

The CASTLE-AF (Catheter Ablation Versus Standard Conventional Treatment in Patients with Left Ventricular Dysfunction and Atrial Fibrillation) trial was published in 2018 by Marrouche et al. ${ }^{46}$ It was an international, prospective, randomised, multicentre trial evaluating the effectiveness of catheter ablation for AF in patients with HF, comparing mortality and morbidity with a medical treatment control arm. A total of 398 patients from 33 sites in Europe, USA, and Australia were included. Inclusion criteria were symptomatic paroxysmal or persistent
AF; failure, intolerance or unwillingness to take antiarrhythmic drugs; left ventricular dysfunction with a LVEF $\leq 35 \%$ measured in the last 6 weeks prior to enrolment; New York Heart Association (NYHA) class 22; and an implantable cardioverter defibrillator (ICD) for primary or secondary prevention (with atrial sensing capabilities) or a cardiac resynchronisation therapy defibrillator (CRT-D) device, both with remote monitoring technology (Home Monitoring ${ }^{\circledast}$, Biotronik SE \& Co. KG, Berlin, Germany). The primary endpoint was all-cause mortality or worsening of HF requiring unplanned hospitalisation. Major secondary endpoints included event rates for cerebrovascular accidents, cardiovascular mortality, unplanned hospitalisation due to cardiovascular disease, all-cause hospitalisation, quality of life as evaluated by the Minnesota Living with Heart Failure (MLWHF) and the European Quality of Life 5 Dimensions (EuroQoL EQ-5D) questionnaires, and exercise tolerance evaluated by a 6-minute walk test. 
Table 2: Study characteristics of randomised controlled trials comparing catheter ablation for atrial fibrillation with different comparator arms in patients with heart failure with reduced ejection fraction

\begin{tabular}{|c|c|c|c|c|c|c|c|c|c|}
\hline Study (year) & $\begin{array}{l}\mathrm{N}(\mathrm{CA} / \\
\text { comp. } \\
\text { arm) }\end{array}$ & Type of AF & $\begin{array}{l}\text { Mean } \\
\text { follow-up } \\
\text { (months) }\end{array}$ & $\begin{array}{l}\text { Post-ablation } \\
\text { heart rhythm } \\
\text { assessment } \\
\text { method }\end{array}$ & $\begin{array}{l}\text { Ablation } \\
\text { technique }\end{array}$ & $\begin{array}{l}\text { Ablation } \\
\text { strategy }\end{array}$ & Comp. arm & $\begin{array}{l}\text { Primary } \\
\text { endpoint }\end{array}$ & Result \\
\hline $\begin{array}{l}\text { Khan et al., } \\
2008^{40}\end{array}$ & $81(41 / 40)$ & $\begin{array}{l}\text { Persistent } \\
50 \%, \\
\text { paroxysmal } \\
50 \%\end{array}$ & 6 & Loop recorder & RF & $\begin{array}{l}\text { PVI } \pm \text { linear } \\
\text { lesions and } \\
\text { CFAE }\end{array}$ & $\begin{array}{l}\text { AVN ablation } \\
\text { + BiVpacing }\end{array}$ & $\begin{array}{l}\text { Change in LVEF, } \\
6 \mathrm{MWT} \text { and } \\
\text { MLWHF score }\end{array}$ & $\begin{array}{l}\text { Improved LVEF, 6MWT } \\
\text { and QoL score in PVI } \\
\text { group (6-month f/u) }\end{array}$ \\
\hline $\begin{array}{l}\text { MacDonald } \\
\text { et al., } 2011^{41}\end{array}$ & $41(22 / 19)$ & Persistent & 6 & $\begin{array}{l}\text { 24-h Holter } \\
\text { monitor }\end{array}$ & RF & $\begin{array}{l}\mathrm{PVI} \pm \text { linear } \\
\text { lesions and } \\
\text { CFAE } \pm \text { CVTI } \\
\text { (+ } 3 \text { months } \\
\text { amiodarone) }\end{array}$ & $\begin{array}{l}\text { Rate control } \\
\text { with } \mathrm{BB} \pm \mathrm{Dig}\end{array}$ & Change in LVEF & $\begin{array}{l}\text { No difference in LVEF } \\
\text { between groups; no } \\
\text { difference in BNP, 6MWT } \\
\text { or QoL (12-month f/u) }\end{array}$ \\
\hline $\begin{array}{l}\text { Jones et al., } \\
2013^{42}\end{array}$ & $52(26 / 26)$ & Persistent & 12 & $\begin{array}{l}\text { 48-h Holter } \\
\text { monitor }\end{array}$ & RF & $\begin{array}{l}\mathrm{PVI} \pm \text { linear } \\
\text { lesions and } \\
\mathrm{CFAE} \pm \mathrm{CVTI}\end{array}$ & $\begin{array}{l}\text { Rate control } \\
\text { with } \mathrm{BB} \pm \text { Dig }\end{array}$ & $\begin{array}{l}\text { Change in } \\
\text { peak oxygen } \\
\text { consumption }\end{array}$ & $\begin{array}{l}\text { Improvement in } \\
\text { exercise performance } \\
\text { and BNP in ablation arm } \\
\text { (12-month } \mathrm{f} / \mathrm{u})\end{array}$ \\
\hline $\begin{array}{l}\text { Hunter } \\
\text { et al., } 2014^{43}\end{array}$ & $50(26 / 24)$ & Persistent & 6 & $\begin{array}{l}\text { 48-h Holter } \\
\text { monitor }\end{array}$ & RF & $\begin{array}{l}\text { PVI with } \\
\text { CFAE } \pm \text { linear } \\
\text { lesions } \pm \text { CVTI }\end{array}$ & Rate control & Change in LVEF & $\begin{array}{l}\text { Improved LVEF, better } \\
\text { exercise performance } \\
\text { and QoL score in } \\
\text { ablation arm (12-month } \\
\text { f/u) }\end{array}$ \\
\hline $\begin{array}{l}\text { Di Biase } \\
\text { et al., } 2016^{44}\end{array}$ & $\begin{array}{l}203 \\
(102 / 101)\end{array}$ & Persistent & 24 & ICD/CRT-D & RF & $\begin{array}{l}\text { PVI + LAPWI + } \\
\text { SVCI + CFAE }\end{array}$ & Amiodarone & AF recurrence & $\begin{array}{l}\text { Improved AF } \\
\text { recurrence free } \\
\text { survival, lower mortality } \\
\text { and unplanned } \\
\text { hospitalisations in } \\
\text { ablation arm }\end{array}$ \\
\hline $\begin{array}{l}\text { Prabhu } \\
\text { et al., } 2017^{45}\end{array}$ & $66(33 / 33)$ & Persistent & 6 & Loop recorder & RF CF & $P V I+L A P W I$ & Rate control & Change in LVEF & $\begin{array}{l}\text { Improved LVEF in } \\
\text { ablation arm; those who } \\
\text { were LGE negative had } \\
\text { greater improvements } \\
\text { in LVEF }\end{array}$ \\
\hline $\begin{array}{l}\text { Marrouche } \\
\text { et al., } 2018^{46}\end{array}$ & $\begin{array}{l}363 \\
(179 / 184)\end{array}$ & $\begin{array}{l}\text { Persistent } \\
70 \% \\
\text { paroxysmal } \\
30 \%\end{array}$ & 38 & ICD/CRT-D & $\begin{array}{l}\text { Operator } \\
\text { decision }\end{array}$ & $\begin{array}{l}\mathrm{PVI}+\text { operator } \\
\text { decision }\end{array}$ & $\begin{array}{l}\text { Rate or } \\
\text { rhythm } \\
\text { control }\end{array}$ & $\begin{array}{l}\text { Mortality and } \\
\text { heart failure } \\
\text { hospitalisation }\end{array}$ & $\begin{array}{l}\text { Improved primary } \\
\text { composite end-point } \\
\text { of mortality + HF } \\
\text { hospitalisation in } \\
\text { ablation arm }\end{array}$ \\
\hline
\end{tabular}

GMWT = 6-minute walk test; $A F=$ atrial fibrillation; $A V N=$ atrioventricular node; $B B=$ beta blocker; Bivpacing = biventricular pacing; $B N P=B$-type natriuretic peptide; $C A=$ catheter ablation; $C F=$ contact force; $C F A E=$ complex fractionated atrial electrogram; comp. arm = comparator arm; $C R T-D=c a r d i a c$ resynchronisation therapy defibrillation; $\mathrm{CVTI}=$ cavotricuspid isthmus; Dig = digitalis; $f / \mathrm{l}=$ follow-up; HF = heart failure; ICD = implantable cardioverter defibrillator; $L A P W I=$ left atrial posterior wall isolation; $L G E$ = late gadolinium enhancement; $L V E F=$ left ventricular ejection fraction; $M L W H F=$ Minnesota living with heart failure; $N=$ number; $P V I=$ pulmonary vein isolation; $\mathrm{QOL}=$ Quality of life; $R \mathrm{~F}=$ radiofrequency; $\mathrm{SVCl}=$ superior vena cava isolation.

\section{There were three key results of CASTLE-AF:}

1. catheter ablation of AF in patients with HF was associated with a $38 \%$ reduction in death or hospitalisation for worsening HF;

2. catheter ablation of AF in patients with HF was associated with a $47 \%$ reduction in death from any cause; and

3. catheter ablation of AF in patients with HF was associated with a $44 \%$ reduction in hospitalisation for worsening HF.

CASTLE-AF is currently the most optimistic and robust trial indicating prognostic benefits of AF ablation. An overview over study details is given in Table 3. It is the first, large randomised study providing clinical evidence that ablation of $\mathrm{AF}$ improves hard outcome parameters in patients with HF. Catheter ablation for patients with HF and concomitant AF who fit the inclusion criteria of CASTLE-AF is now supported by robust evidence as a first-line therapy during the course of HF. The results strongly indicate that catheter ablation of AF is a crucial element in managing advanced $\mathrm{HF}$, alongside CRT and continuous remote monitoring. Limitations of the study include its relatively small and highly selected patient cohort and the lack of blinding.

\section{AATAC}

The AATAC (Ablation Versus Amiodarone for Treatment of Persistent Atrial Fibrillation in Patients With Congestive Heart Failure and an Implanted Device) trial, published by Di Biase et al., was designed to address whether AF ablation is superior to a pharmacological rhythm control strategy with amiodarone, with regards to AF-free survival in patients with symptomatic (NYHA II-III) HFrEF (LVEF $\leq 40 \%$ ) and persistent AF. ${ }^{44}$ AATAC was a multicentre, parallel-group, open-label, randomised controlled trial including 203 patients; 102 randomised to catheter ablation and 101 for amiodarone treatment. Inclusion criteria were age $\geq 18$ years, persistent $A F$, dual chamber ICD or CRT-D in place, NYHA II-II, and LVEF $\leq 40 \%$ 
Table 3: Study details of the CASTLE-AF trial

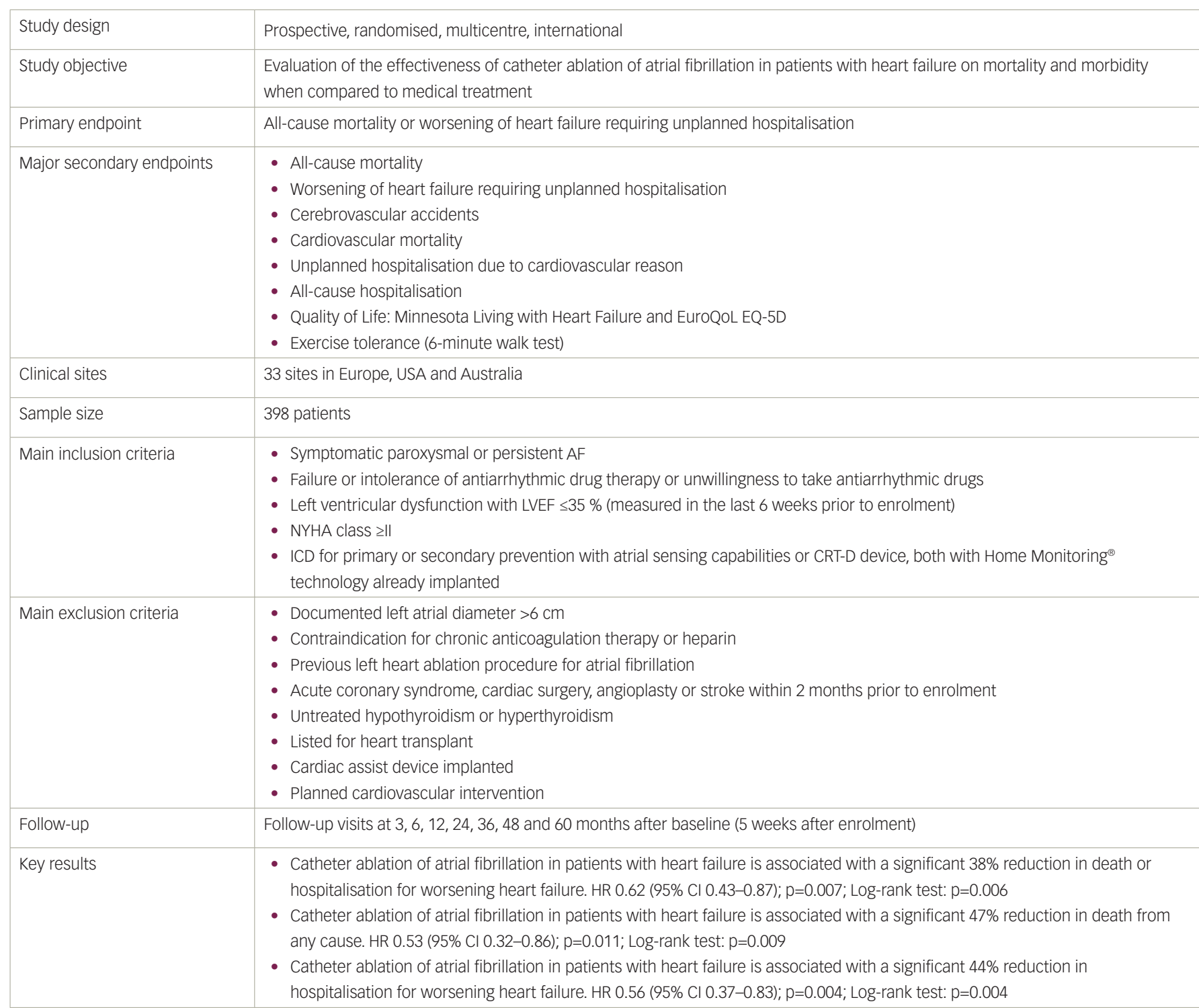

$A F=$ atrial fibrillation; CASTLE = Catheter Ablation Versus Standard Conventional Treatment in Patients with Left Ventricular Dysfunction and Atrial Fibrillation; $C l=$ confidence interval; $C R T-D=$ cardiac resynchronisation therapy - defibrillator; $H R=$ hazard ration; ICD = implantable cardioverter defibrillator; $L V E F=$ left ventricular ejection fraction; NYHA = New York Heart Association; $Q O L=$ quality of life

within the last 6 months. The primary and secondary outcomes of this study were all in favour of a catheter ablation strategy. This included the primary endpoint of atrial arrhythmia-free survival at 2 years (71 patients in the ablation group [70.0\%; $95 \% \mathrm{Cl} 60-78 \%$ ] versus 34 patients in the control group (34.0\%; $95 \% \mathrm{Cl} 25-44 \%]$; $\mathrm{p}<0.001$ ) and secondary outcomes including unplanned hospitalisation (32 [31.0\%; 95\% Cl 20-41\%] versus 58 [57.0\%; 95\% Cl 51-69] [risk ratio \{RR\} 0.55; 95\% Cl 0.39-0.76; number needed to treat 3.8; $p<0.001]$ ), death (8 [8.0\%] versus 18 [18.0\%; RR 0.44; $95 \% \mathrm{Cl}$ -0.20-0.96; number needed to treat 10; $\mathrm{p}=0.037]$ ), LVEF (change from baseline to follow-up, $8.1[ \pm 4]$ versus $4.0[ \pm 5]$; $p=0.02)$, 6-minute walk distance (change from baseline to follow-up, $22[ \pm 22]$ versus $10[ \pm 37]$; $\mathrm{p}=0.02$ ), and MLWHF (Minnesota Living with Heart Failure) Score (change from baseline to follow-up, $11[ \pm 19]$ versus $6[ \pm 17] ; p=0.04)$.

One of the major criticisms, however, regarding these results is that this was a small, highly selected cohort and the trial was not designed to assess clinical outcomes like hospitalisation for HF and death, and that these results therefore require secondary validation with an appropriately powered study.

\section{CAMERA-MRI}

The CAMERA-MRI (Catheter Ablation Versus Medical Rate control in Atrial Fibrillation and Systolic Dysfunction) trial was a randomised clinical trial to evaluate medical rate control compared with catheter ablation for improvement of left ventricular systolic dysfunction in patients with $\mathrm{AF}$ and idiopathic cardiomyopathy (LVEF $\leq 45 \%$ ). ${ }^{45}$ Sixty-eight patients were enrolled and cardiac magnetic resonance (CMR) was used to evaluate LVEF at baseline and 6 months after randomisation. At 6 months follow-up, LVEF normalised to $\geq 50 \%$ in $58 \%$ of the catheter ablation group compared with only $9 \%$ in the medical rate control group. The authors concluded that catheter ablation is a promising strategy for improving LVEF in patients with AF and left ventricular systolic dysfunction and that catheter ablation may be superior to medical rate control in this cohort. It is likely that a significant proportion of patients with persistent AF and otherwise unexplained left ventricular systolic dysfunction have an under-recognised arrhythmia-related cardiomyopathy and efforts to restore sinus rhythm should be considered in selected patients. 


\section{CAMTAF}

The CAMTAF trial (Catheter Ablation Versus Medical Treatment of Atrial Fibrillation in Heart Failure) was published in 2014 by Hunter et al. ${ }^{43}$ The authors compared the effect of a catheter ablation strategy with that of medical rate control in patients with persistent AF and HF. The primary endpoint was the difference between groups in LVEF at 6 months. Secondary endpoints included the percentage reduction in left ventricular end systolic volume, $\mathrm{VO}_{2} \max$, plasma B-type natriuretic peptide (BNP), HYHA class, MLWHF score, and 36-item Short-Form score (SF-36). The results demonstrated that a catheter ablation strategy in patients with persistent AF and HF resulted in improved left ventricular function, functional capacity, HF symptoms and quality of life compared with medical rate control, suggesting a beneficial effect of catheter ablation in treating selected patients with $\mathrm{AF}$ and $\mathrm{HF}$.

\section{PABA-CHF}

Khan et al. published the PABA-CHF (Pulmonary Vein Antrum Isolation versus AV Node Ablation with Bi-Ventricular Pacing for Treatment of Atrial Fibrillation in Patients with Congestive Heart Failure) trial in $2008 .{ }^{40}$ In this prospective, multicentre, randomised, controlled trial, patients with symptomatic, drug-resistant AF, an LVEF of $\leq 40 \%$, and HF NYHA class ॥ or III, were assigned either to PVI or atrioventricular (AV) node ablation with biventricular pacing. The primary endpoint was a composite of LVEF, distance achieved on the 6-minute walk test, and MLWHF score. All criteria improved with $\mathrm{PVI}$, with all three components demonstrating statistically significant improvements. For PVI as compared with AV node ablation with biventricular pacing, LVEF was significantly higher (35 $\pm 9 \%$ versus $28 \pm 6 \%$; $p<0.001)$, the 6-minute walking distance significantly longer ( $340 \pm 49 \mathrm{~m}$ versus $297 \pm 36 \mathrm{~m} ; \mathrm{p}<0.001$ ), and the MLWHF scores significantly better $(60 \pm 8$ versus $82 \pm 14 ; p<0.001)$. Thus, PVI was superior to AV node ablation and biventricular pacing in patients with HF who had drug-refractory AF.

\section{ARC-HF}

Jones et al. published a randomised, open-label, blinded-endpoint clinical trial in 2013,42 which compared catheter ablation with medical rate control for persistent AF in HF; it was called ARC-HF (Catheter Ablation Versus Rate Control in the Management of Persistent Atrial Fibrillation in Heart Failure) trial. Patients were followed up at 3, 6 and 12 months. The primary endpoint, peak $\mathrm{VO}_{2}$, was defined at 12 months and also measured at 3 months. Secondary endpoints included quality of life, BNP, 6-minute walk distance, and ejection fraction. Results were analysed by intention-to-treat. Peak oxygen consumption significantly increased after catheter ablation compared with rate control (difference $+3.07 \mathrm{~mL} / \mathrm{kg} / \mathrm{min} ; 95 \% \mathrm{Cl}$ 0.56-5.59; $\mathrm{p}=0.018$ ). However, the change was not evident after 3 months. Catheter ablation improved the MLWHF score $(p=0.019)$ and $B N P(p=0.045)$ at 12 months.

\section{Other randomised controlled trials}

Study results by MacDonald et al. published in 2011 were different from the promising results of the other trials. The aim of this study was to determine whether or not radiofrequency ablation (RFA) for persistent AF in patients with advanced HF leads to improvements in cardiac function. ${ }^{41}$ Patients were randomised to radiofrequency ablation or continued medical rate control therapy. These results suggested that radiofrequency ablation did not improve LVEF measured by cardiac MRI compared with a medical rate control strategy. Radiofrequency ablation resulted in long-term restoration of sinus rhythm in only 50\% of patients. It did improve radionuclide LVEF, but did not improve other secondary outcomes and was associated with a significant rate of serious complications.

\section{Meta-analyses and reviews}

The seven previously mentioned randomised controlled trials have also been analysed in several meta-analyses and reviews. ${ }^{13,47-53} \mathrm{AlTurki}$ et al. ${ }^{47}$ summarised all seven trials (Khan et al., ${ }^{40}$ MacDonald et al., ${ }^{41}$ Jones et al. ${ }^{42}$ Hunter et al. ${ }^{43}$ Di Biase et al.. ${ }^{44}$ Prabhu et al., ${ }^{45}$ and Marrouche et al. ${ }^{46}$ ). They found a significant reduction in mortality (RR 0.50; 95\% Cl 0.34-0.74; $\mathrm{p}=0.0005$ ) and HF-related hospitalisations (RR 0.56; 95\% Cl 0.44-0.71; $\mathrm{p}<0.0001)$ in the ablation arm compared with medical therapy including antiarrhythmic drugs. Additionally, they found significant improvements in LVEF following catheter ablation (weighted mean difference 7.48; 95\% Cl 3.71-11.26; $p<0.0001$ ). All seven trials were also analysed by Briceño et al. ${ }^{52}$ Ruzieh et al., ${ }^{49}$ and Ma et al. ${ }^{53}$ All found favourable effects of catheter ablation as compared to conventional treatment with regard to mortality, HF-related hospitalisations, improvement of LVEF, functional capacity, and quality of life. Turagam et al., ${ }^{48}$ Smer et al., ${ }^{51}$ and Elgendy et $a .^{50}$ analysed only six of the seven trials excluding the study by Khan et al., as the comparator arm of this study was AV node ablation and biventricular pacing instead of drug therapy. The results of these meta-analyses are listed in Table 4.

\section{Studies on catheter ablation of atrial fibrillation in patients with heart failure with mid-range or preserved ejection fraction}

There have only been few studies regarding catheter ablation for AF in patients with HFmrEF or preserved ejection fraction (HFPEF). Cha et al. enrolled 368 patients in a prospective cohort study; ${ }^{29} 157$ with diastolic dysfunction (HFpEF), 111 with systolic dysfunction (HFrEF), and 100 patients in a control group with normal left ventricular function. After 1 year, there was no statistically significant difference in AF recurrence between patients with diastolic dysfunction and the control group. After 5 years, however, freedom from AF recurrence was about $40 \%$ in the diastolic dysfunction group and $65 \%$ in the control group, which was statistically significant. Thirty percent of patients with HFpEF showed at least one grade improvement in diastolic dysfunction and significant improvement in the physical components of the SF-36 questionnaire.

In 2013, Machino-Ohtsuka et al. published a study evaluating 74 patients with HFpEF undergoing catheter ablation for $\mathrm{AF}^{.54}$ Average follow-up was 34 months. Drug-free success rate after one and multiple procedures was $27 \%$ and $45 \%$, respectively. The success rate could be increased to $73 \%$ with pharmaceutical assistance. The study provided evidence in support of the safety and efficacy of catheter ablation on those patients; however, there was no comparator arm.

A recent retrospective study by Black-Maier et al. enrolled 97 patients with HFrEF and 133 patients with HFpEF who were evaluated after ablation. ${ }^{55}$ The outcome of both patient groups was similar. There were no significant differences in procedure time, adverse events, arrhythmia recurrence, or functional improvement (Mayo AF Symptom Inventory and NYHA class).

\section{Discussion}

These trial results show that in patients with $\mathrm{AF}$ and HFrEF the outcomes of catheter ablation compared to conventional treatment are superior with regard to all-cause mortality, hospitalisation for $\mathrm{HF}$, improvement of LVEF, quality of life, and functional capacity, while complication rates are comparable between the two treatment strategies. Some of the earlier randomised controlled trials, however, included only small numbers of patients and were only adequately powered to assess surrogate end-points like LVEF, exercise capacity, and quality of life. Additionally, the ablation strategies in these trials were heterogeneous, and some of 
Table 4: Comparison of meta-analyses summarising randomised, controlled trials on catheter ablation of atrial fibrillation in patients with heart failure with reduced ejection fraction

\begin{tabular}{|c|c|c|c|c|c|c|c|}
\hline & $\begin{array}{l}\text { Briceño et al., } \\
2018^{52}\end{array}$ & Ma et al., $2018^{53}$ & $\begin{array}{l}\text { AlTurki et al., } \\
2019^{47}\end{array}$ & Ruzieh et al., $2019^{49}$ & $\begin{array}{l}\text { Elgendy et al., } \\
2018^{50}\end{array}$ & $\begin{array}{l}\text { Smer et al., } \\
2018^{51}\end{array}$ & $\begin{array}{l}\text { Turagam et } \\
\text { al., } 2019^{48}\end{array}$ \\
\hline $\begin{array}{l}\text { Trials included } \\
\text { [Ref] }\end{array}$ & [40-46] & [40-46] & [40-46] & [40-46] & [41-46] & [41-46] & {$[41-46]$} \\
\hline $\begin{array}{l}\text { All-cause } \\
\text { mortality }\end{array}$ & $\begin{array}{l}\text { OR 0.46; } \\
\text { Cl } 0.29 \text { to } 0.72 ; \\
p=0.0007\end{array}$ & $\begin{array}{l}\text { RR 0.52; } \\
\text { Cl } 0.35 \text { to } 0.76 ; \\
p=0.0009\end{array}$ & $\begin{array}{l}\text { RR 0.50; } \\
\text { Cl } 0.34 \text { to } 0.74 ; \\
p=0.0005\end{array}$ & $\begin{array}{l}\text { OR 0.49; } \\
\text { Cl } 0.31 \text { to } 0.77 ; \\
p=0.002\end{array}$ & $\begin{array}{l}\text { RR 0.50; } \\
\text { Cl } 0.34 \text { to } 0.74 ; \\
p<0.0001\end{array}$ & $\begin{array}{l}\text { OR } 0.46 ; \\
\text { Cl } 0.29 \text { to } 0.73 ; \\
p=0.0009\end{array}$ & $\begin{array}{l}\text { RR } 0.52 ; \mathrm{Cl} \\
0.33 \text { to } 0.81\end{array}$ \\
\hline $\begin{array}{l}\text { Heart failure } \\
\text { related } \\
\text { hospitalisation }\end{array}$ & - & $\begin{array}{l}\text { RR 0.58; } \\
\text { Cl } 0.46 \text { to } 0.66 ; \\
p<0.00001\end{array}$ & $\begin{array}{l}\text { RR 0.56; } \\
\text { Cl } 0.44 \text { to } 0.71 ; \\
p<0.0001\end{array}$ & $\begin{array}{l}\text { OR 0.43; } \\
\text { Cl } 0.29 \text { to } 0.64 ; \\
p<0.001\end{array}$ & $\begin{array}{l}\text { RR 0.58; } \mathrm{Cl} 0.41 \text { to } \\
0.81 ; p=0.002\end{array}$ & $\begin{array}{l}\text { OR 0.43; } \\
\text { Cl } 0.30 \text { to } 0.62 ; \\
p<0.00001\end{array}$ & $\begin{array}{l}\text { RR 0.60; } \mathrm{Cl} \\
0.39 \text { to } 0.93\end{array}$ \\
\hline $\begin{array}{l}\text { Cerebrovascular } \\
\text { accident }\end{array}$ & - & $\begin{array}{l}\text { RR } 0.56 ; \mathrm{Cl} 0.23 \text { to } \\
1.36 ; p=0.20\end{array}$ & - & - & - & $\begin{array}{l}\text { OR 0.49; } \mathrm{Cl} \\
0.18-1.35 ; p=0.17\end{array}$ & - \\
\hline Change in LVEF & $\begin{array}{l}\text { SMD 0.68; } \\
\text { Cl } 0.28 \text { to } 1.08 ; \\
p=0.0009\end{array}$ & $\begin{array}{l}\text { MD 7.57; } \\
\text { Cl } 3.72 \text { to } 11.41 ; \\
p=0.0001\end{array}$ & $\begin{array}{l}\text { WMD 7.48; } \\
\text { Cl } 3.71 \text { to 11.26; } \\
p<0.0001\end{array}$ & $\begin{array}{l}\text { MD } 6.8 \% ; \mathrm{Cl} 3.5 \text { to } \\
10.1 ; p<0.001\end{array}$ & $\begin{array}{l}\text { SMD 2.58; } \mathrm{Cl} 0.88 \\
\text { to } 4.27 ; p=0.003\end{array}$ & $\begin{array}{l}\text { MD 5.93; } \\
\text { Cl } 3.59 \text { to 8.27; } \\
p<0.00001\end{array}$ & $\begin{array}{l}\text { MD } 6.95 \% ; C l \\
3.0 \text { to } 10.9 \%\end{array}$ \\
\hline $\begin{array}{l}\text { 6-minute walk } \\
\text { test [m] }\end{array}$ & $\begin{array}{l}\text { SMD } 0.51 ; \mathrm{Cl} 0.13 \\
\text { to } 0.90 ; p=0.008\end{array}$ & $\begin{array}{l}\text { MD 26.67; } \mathrm{Cl} 12.07 \\
\text { to } 41.27 ; p=0.62 ; \\
p=0.0003\end{array}$ & $\begin{array}{l}\text { WMD } 30.15 ; C l \\
10.47 \text { to } 49.84 ; \\
p<0.0001\end{array}$ & $\begin{array}{l}\text { MD } 29.3 ; \mathrm{Cl} 11.8 \text { to } \\
46.8 ; p=0.001\end{array}$ & - & $\begin{array}{l}\text { MD } 24.65 ; \mathrm{Cl} \\
11.18 \text { to } 38.12 ; \\
p=0.0003 \text { (versus } \\
\text { rate control) }\end{array}$ & $\begin{array}{l}\text { MD 20.93; Cl } \\
5.91 \text { to } 35.95\end{array}$ \\
\hline $\begin{array}{l}\text { Quality of } \\
\text { life (MLWHF } \\
\text { questionnaire) }\end{array}$ & $\begin{array}{l}\text { SMD }-0.69 ; C l-1.29 \\
\text { to }-0.09 ; p=0.02\end{array}$ & $\begin{array}{l}\text { MD }-9.49 ; C l-14.64 \\
\text { to }-4.34 ; p=0.0003\end{array}$ & $\begin{array}{l}\text { WMD }-9.53 ; C l \\
-14.67 \text { to }-4.38 ; \\
p<0.0001\end{array}$ & $\begin{array}{l}\mathrm{MD}-12.1 ; \mathrm{Cl}-20.9 \text { to } \\
-3.3 ; \mathrm{p}=0.007\end{array}$ & $\begin{array}{l}\text { SMD }-0.40 ; C l-0.65 \\
\text { to }-0.14 ; p=0.002\end{array}$ & $\begin{array}{l}M D-9.01 ; C l \\
-15.56 \text { to }-2.45 ; \\
p=0.007\end{array}$ & $\begin{array}{l}\mathrm{MD}-9.02 ; \mathrm{Cl} \\
-19.75 \text { to } 1.71\end{array}$ \\
\hline $\begin{array}{l}\text { Functional } \\
\text { capacity (peak } \\
\mathrm{VO}_{2} \text { ) }\end{array}$ & - & $\begin{array}{l}\text { MD 3.16; } \mathrm{Cl} 1.09 \text { to } \\
5.23 ; p=0.003\end{array}$ & - & - & - & $\begin{array}{l}\text { MD 3.16; } \\
\text { Cl 1.04 to 5.29; } \\
p=0.004\end{array}$ & $\begin{array}{l}\text { MD } 3.17 ; C l \\
1.26 \text { to } 5.07\end{array}$ \\
\hline NYHA class & - & $\begin{array}{l}\text { MD }-0.74 ; C l-0.83 \\
\text { to }-0.64 ; p<0.00001\end{array}$ & - & - & - & - & - \\
\hline Adverse events & $\begin{array}{l}\text { OR } 1.13 ; \mathrm{Cl} 0.58 \text { to } \\
2.20 ; p=0.71\end{array}$ & - & $\begin{array}{l}7.3 \% ; \mathrm{Cl} 3.4 \text { to } \\
11.3 \%\end{array}$ & - & $\begin{array}{l}7.3 \% ; \mathrm{Cl} 3.4 \text { to } \\
11.3 \%\end{array}$ & $\begin{array}{l}\text { OR } 1.18 ; \mathrm{Cl} 0.44 \text { to } \\
3.15 ; p=0.75\end{array}$ & $\begin{array}{l}\text { RR } 1.68 ; \mathrm{Cl} \\
0.58 \text { to } 4.85\end{array}$ \\
\hline
\end{tabular}

The meta-analyses by Briceño et al., ${ }^{52} \mathrm{Ma}$ et al., ${ }^{53}$ AlTurki et al.., ${ }^{47}$ and Ruzieh et al. ${ }^{49}$ analysed all seven trials by Khan et al., ${ }^{40}$ MacDonald et al., ${ }^{41}$ Jones et al., ${ }^{42}$ Hunter et al., ${ }^{43}$ Di Biase et al., ${ }^{44}$ Prabhu et al., ${ }^{45}$ and Marrouche et al. ${ }^{46}$ The meta-analyses by Elgendy et al., ${ }^{50}$ Smer et al.., and Turagam et al. ${ }^{48}$ excluded the study by Khan, as the comparator arm in this study was not medical therapy but atrioventricular nodal ablation plus biventricular pacing. There was a significant benefit in the ablation arm concerning all-cause mortality, hospitalisation for heart failure, left ventricular ejection fraction, 6-minute walk test, quality of life, peak oxygen consumption and NYHA class. On the other hand, numbers of cerebrovascular accidents and adverse events did not significantly differ.

$\mathrm{Cl}=$ confidence interval (95\%); LVEF = left ventricular ejection fraction; $m=$ metres; $M D=$ mean difference; MLWHF = Minnesota Living With Heart Failure; $N Y H A=$ New York Heart Association; $O R=$ odds ratio; $R$ ef = reference; $R R=$ risk ratio; $S M D=$ standard mean difference; $V_{2}=$ oxygen consumption; WMD = weighted mean difference.

them have already been abandoned. ${ }^{3}$ While PVI is still the cornerstone of catheter ablation for paroxysmal and persistent AF and left posterior wall isolation has shown promising results, routine ablation of complex fractionated atrial electrograms and linear lesion formation are no longer used since the disappointing results of STAR AF $\|$ and other trials. ${ }^{4,56,57}$ The most important trial in this context is probably CASTLE-AF, published in 2018, which assessed the impact of AF ablation on mortality and HF progression rates. Overall, the findings of these trials seem understandable as patients with $\mathrm{HF}$ carry an increased risk of $A F$, while $A F$ is a risk factor for the development of HF. More than half of patients with HF have AF, and one in three patients with $\mathrm{AF}$ develops $\mathrm{HF}^{58}$ These frequently coexisting conditions are among the most common cardiovascular diagnoses associated with hospital admission, morbidity, and mortality. ${ }^{59}$

These data resulted in a new recommendation in the 2019 AHA/ACC/HRS Focused Update of the 2014 AHA/ACC/HRS Guideline for the Management of Patients With Atrial Fibrillation: 'AF catheter ablation may be reasonable in selected patients with symptomatic AF and HF with reduced left ventricular (LV) ejection fraction (HFrEF) to potentially lower mortality rate and reduce hospitalization for $\mathrm{HF}^{\prime}$ (III indication). ${ }^{10}$ This indication clearly exceeds mere symptom control in this selected group of patients. It does not mention a previous ICD or CRT-D implantation. The latter, however, was an inclusion criterion of AATAC and CASTLE-AF. In clinical practice, AF ablation in patients with HFrEF is often performed before the implantation of an ICD or CRT-D, because device implantation may no longer be indicated in case of an improved LVEF after the ablation.

Contrasting evidence to the favourable results of AF ablation in patients with HFrEF, however, was published by Roy et al. in 2008.60 In their multicentre, randomised Atrial Fibrillation in Congestive Heart Failure trial they compared rhythm control with rate control in patients with a LVEF of $\leq 35 \%$, symptoms of congestive HF, and a history of AF. The primary outcome was the time to death from cardiovascular causes. Rhythm control was mainly achieved by electrical cardioversion and drug therapy with amiodarone, sotalol and dofetilide, rate control with beta-blockers and digitalis. AV nodal ablation and pacemaker therapy were recommended for patients who did not meet the rate-control targets with drug therapy. In this study, rhythm control did not reduce the rate of death from cardiovascular causes, as compared with a rate-control strategy.

According to current guidelines, patients with HF are classified as those with reduced (HFrEF, LVEF <40\%), mid-range (HFmrEF, LVEF 
40-49\%), and preserved (HFpEF, LVEF $\geq 50 \%$ ) ejection fraction. ${ }^{61}$ Data on long-term outcomes after catheter ablation for $\mathrm{AF}$ in patients with HFMrEF or HFpEF are sparse. Recently, Zafrir et al.62 investigated long-term implications of AF compared to sinus rhythm in patients with all three categories of HF. They analysed data from the observational, prospective, HF long-term registry of the European Society of Cardiology. A total of 14,964 patients with HF were enrolled. The prevalence of AF was $27 \%$ in $\mathrm{HFrEF}, 29 \%$ in HFmrEF, and $39 \%$ in HFpEF. This increasing prevalence of $A F$ in patients with less systolic dysfunction seems to be counterintuitive at first glance. It can be explained by the physiological milieu associated with HFPEF with elevated filling pressure and myocardial fibrosis, which probably increases the risk pf AF.59 After multivariate adjustment, the HR of AF for HF hospitalisations was 1.036 in HFrEF (95\% Cl 0.888-1.208; $\mathrm{p}=0.652), 1.430$ in HFMrEF $(95 \% \mathrm{Cl}$ 1.087-1.882; $\mathrm{p}=0.011$ ), and 1.487 in HFpEF (95\% Cl 1.195-1.851; $p<0.001)$. For combined all-cause death or HF hospitalisations, HR was 0.957 for HFrEF (95\% Cl 0.843-1.087; $\mathrm{p}=0.502)$, 1.302 for HFmrEF (95\% Cl 1.055-1.608; $\mathrm{p}=0.014)$, and 1.365 for HFpEF $(95 \% \mathrm{Cl} 1.152-1.619$; p $<0.001)$. In patients with HFrEF, AF was not associated with worse outcomes in those with either an acute or a chronic presentation of HF. The authors concluded that the prevalence of AF increases with increasing ejection fraction. Its association with worse cardiovascular outcomes remained significant in patients with HFpEF and HFmrEF, but not in those with HFrEF. Despite these observations, no pharmacological or device-based therapies have been consistently shown to offer meaningful improvements in hard clinical outcomes in HFpEF.59 The recently published CASTLE-AF trial was limited to patients with an ejection fraction $\leq 35 \% .{ }^{46}$ But if AF has a larger adverse impact on patients with HFpEF and HFmrEF than on those with HFrEF, a durable restoration of sinus rhythm could confer an even larger benefit in HFpEF patients.

Despite limitations in the study by Zafrir et al., and conflicting results of other trials showing similar prognostic relevance of $\mathrm{AF}$ in all three categories of patients with $A F^{63} A F$ treatment in the subgroup of HFpEF seems to be a promising therapeutic target. Thus, more randomised controlled trials on AF ablation for patients with HFmrEF and HFpEF will be needed in the future. The CABANA trial, the full manuscript of which has not yet been published, and which included patients with all categories of HF, did not meet the primary endpoint of a composite of total mortality, disabling stroke, serious bleeding, or cardiac arrest in the intention-to-treat analysis indicating that ablation is not superior to drug therapy for cardiovascular outcomes at 5 years among patients with new-onset or untreated AF requiring therapy. The positive outcome of a per protocol analysis, which purists would strictly reject, could serve at least as hypothesis-generating for further trials.

Some clinical trials on AF ablation are currently ongoing. The CONTRA-HF (Ablation of Atrial Fibrillation in Heart Failure Patients; ClinicalTrials.gov identifier NCT03062241) trial will investigate the impact of cryoablation in patients with HF and implanted ICD or CRT-D. Whilst the AMICA (Atrial Fibrillation Management in Congestive Heart Failure With Ablation; ClinicalTrials.gov identifier NCT00652522) trial will investigate whether $\mathrm{PVI}$ alone in patients with persistent AF or longstanding persistent AF improves outcomes compared with best medical therapy. Finally, the RAFT-AF (Randomised Ablation-based Atrial Fibrillation Rhythm Control Trial in Patients with Heart Failure and High Burden Atrial Fibrillation; ClinicalTrials.gov identifier NCT01420393) trial will assess the cost-effectiveness of an ablation strategy in patients with HF as well as assess hard endpoints including all-cause mortality; with patients stratified according to reduced or preserved ejection fraction.

\section{Conclusion}

In previous guidelines, catheter ablation for AF was regarded as predominantly a means for symptom reduction. The favourable effects of AF ablation on stroke, dementia, and other outcomes in patients with AF have been observed in many studies. Emerging data suggest that catheter ablation for AF, especially in the group of patients with HFrEF, has beneficial effects on mortality, hospitalisation for $\mathrm{HF}$, improvement of LVEF, quality of life, and functional capacity, even in those with only mild HF symptoms and no obvious symptoms from the AF itself. The procedure of catheter ablation seems to be safe, as adverse events in the ablation and conventional treatment arms of most trials do not differ significantly. In contrast to the subgroup of HF patients with reduced ejection fraction, there is a lack of data regarding the prognostic benefit of catheter ablation for AF in the subgroups of HFmrEF and HFpEF. Randomised controlled trials to answer that question will be needed in the future. $\mathrm{a}$
1. Calkins H, Kuck KH, Cappato R, et al. 2012 HRS/EHRA/ECAS Expert Consensus Statement on Catheter and Surgical Ablation protion procedura definitions, endpont

2. Arbelo $E$, Brugada J. Hindricks $G$, et al. The atrial fibrillation ablation pilot study: a European Survey on Methodology and results of catheter ablation for atrial fibrillation conducted by the European Heart Rhythm Association. Eur Heart 2014;35:1466-78.

3. Guettler N, Nicol E, Schmitt J, Rajappan K. Mechanisms of atrial fibrillation and their impact on strategies for catheter ablation. European Journal of Arrhythmia \& Electrophysiology. 2018;4:56-64

4. Verma A, Jiang CY, Betts TR, et al. Approaches to catheter ablation for persistent atrial fibrillation. N Eng/ J Med. 2015;372:1812-22

5. Wilber DJ, Pappone C, Neuzil P, et al. Comparison of antiarrhythmic drug therapy and radiofrequency catheter ablation in patients with paroxysmal atrial fibrillation: a randomized controlled trial. JAMA. 2010:303:333-40.

6. Mont L, Bisbal F, Hernandez-Madrid A, et al. Catheter ablation vs. antiarrhythmic drug treatment of persistent atrial fibrillation: a multicentre, randomized, controlled trial (SARA study). Eur Heart J. 2014;35:501-7.

7. Al Halabi S, Qintar M, Hussein A, et al. Catheter ablation for atrial fibrillation in heart failure patients: a meta-analysis of randomized controlled trials. JACC Clin Electrophysio. 2015;1:200-9.

8. Kirchhof P, Benussi S, Kotecha D, et al. 2016 ESC Guidelines for the management of atrial fibrillation developed in collaboration with EACTS. Eur Heart J. 2016;37:2893-962.

9. January CT, Wann LS, Alpert JS, et al. 2014 AHA/ACC/ HRS Guideline for the Management of Patients With Atrial Fibrillation: a report of the American College of Cardiology/ American Heart Association Task Force on Practice Guidelines and the Heart Rhythm Society. J Am Coll Cardiol. 2014;64:e1-76. 10. January CT, Wann LS, Calkins H, et al. 2019 AHA/ACC/HRS Focused Update of the 2014 AHA/ACC/HRS Guideline for the management of patients with atrial fibrillation. Circulation. 2019:139:e000-e000.

11. Bunch TJ, Crandall BG, Weiss JP, et al. Patients treated with catheter ablation for atrial fibrillation have long-term rates of death, stroke, and dementia similar to patients without atrial fibrillation. J Cardiovasc Electrophysiol. 2011;22:839-45.

12. Friberg L, Tabrizi F, Englund A. Catheter ablation for atrial fibrillation is associated with lower incidence of stroke and death: data from Swedish health registries. Eur Heart J. 2016;37:2478-87.

13. Aldaas MA, Malladi CL, Hsu JC. Catheter ablation of atria fibrillation in patients with heart failure. Am J Cardiol. 2019;123:187-95.

14. Wazni OM, Marrouche NF, Martin DO, et al. Radiofrequency ablation vs antiarrhythmic drugs as first-line treatment of symptomatic atrial fibrillation: a randomized trial. JAMA. 2005;293:2634-40.

15. Morillo CA, Verma A, Connolly Ss, et al. Radiofrequency ablation vs antiarrhythmic drugs as first-line treatment of paroxysmal atrial fibrillation (RAAFT-2): a randomized trial. JAMA. 2014;311:692-700.

16. Nielsen JC, Johannessen $A$, Raatikainen $P$, et al. Radiofrequency ablation as initial therapy in paroxysmal atrial fibrillation. N Eng J Med. 2012;367:1589-95.

17. Packer DL, Mark DB, Robb RA, et al. Catheter Ablation versus Antiarrhythmic Drug Therapy for Atrial Fibrillation (CABANA) Trial. Study rationale and design. Am Heart J. 2018:199:192-9.

18. Packer DL, Mark DB, Robb RA, et al. Catheter Ablation vs. Antiarrhythmic Drug Therapy For Atrial Fibrillation: The results of the CABANA multicenter international randomized clinical trial. Abstract B-LBCT01-05. Presented at Heart Rhythm Society Scientific Sessions; 10 May 2018; Boston, MA. Available at: http://abstractsonline.com/pp8/\#1/4554/presentation/7907 (accessed 13 June 2019).
19. Blomström-Lundqvist C, Gizurarson S, Schwieler J, et al. Effect of catheter ablation vs antiarrhythmic medication on quality of life in patients with atrial fibrillation: The CAPTAF randomized clinical trial. JAMA. 2019;321:1059-68.

20. Chen MS, Marrouche NF, Khaykin Y, et al. Pulmonary vein isolation for the treatment of atrial fibrillation in patients with impaired systolic function. J Am Coll Cardiol. patients with impare

21. Hsu LF, Jaïs $P$, Sanders $P$, et al. Catheter ablation for atria fibrillation in congestive heart failure. $N$ Engl J Med. 2004;351:2373-83

22. Tondo $\mathrm{C}$, Mantica M, Russo G, et al. Pulmonary vein vestibule ablation for the control of atrial fibrillation in patients with impaired left ventricular function. Pacing Clin Electrophysiol. 2006;29:962-70.

23. Gentlesk PJ, Sauer WH, Gerstenfeld EP, et al. Reversal of left ventricular dysfunction following ablation of atrial fibrillation. J Cardiovasc Electrophysiol. 2007;18:9-14.

24. Efremidis M, Sideris A, Xydonas S, et al. Ablation of atrial fibrillation in patients with heart failure: reversal of atrial and fibrillation in patients with heart fallure: reversal of atrial and

25. Nademanee K, Schwab MC, Kosar EM, et al. Clinical outcomes of catheter substrate ablation for high-risk patients with atrial fibrillation. J Am Coll Cardiol. 2008;51:843-9.

26. Lutomsky BA, Rostock T, Koops A, et al. Catheter ablation of paroxysmal atrial fibrillation improves cardiac function: a prospective study on the impact of atrial fibrillation ablation on left ventricular function assessed by magnetic resonance imaging. Europace. 2008;10:593-9.

27. De Potter T, Berruezo A, Mont L, et al. Left ventricular systolic dysfunction by itself does not influence outcome of atrial fibrillation ablation. Europace. 2010;12:24-9.

28. Choi AD, Hematpour K, Kukin M, et al. Ablation vs medical therapy in the setting of symptomatic atrial fibrillation and left
ventricular dysfunction. Congest Heart Fail. 2010;16:10-4.

29. Cha YM, Wokhlu A, Asirvatham SJ, et al. Success of ablation for atrial fibrillation in isolated left ventricular diastolic 
dysfunction: a comparison to systolic dysfunction and normal ventricular function. Circ Arrhythm Electrophysiol. 2011:4:724-32.

30. Anselmino M, Grossi S, Scaglione M, et al. Long-term results of transcatheter atrial fibrillation ablation in patients with impaired left ventricular systolic function. J Cardiovasc Electrophysiol. 2013;24:24-32.

31. Calvo N, Bisbal F, Guiu E, et al. Impact of atrial fibrillationinduced tachycardiomyopathy in patients undergoing pulmonary vein isolation. Int I Cardiol. 2013;168:4093-7.

32. Nedios $\mathrm{S}$, Sommer P, Dagres $\mathrm{N}$, et al. Long-term follow-up after atrial fibrillation ablation in patients with impaired left ventricular systolic function: the importance of rhythm and rate control. Heart Rhythm. 2014;11:344-51.

33. Kosiuk J, Nedios S, Darma A, et al. Impact of single atrial fibrillation catheter ablation on implantable cardioverter non-ischaemic cardiomyopathies. Europace. 2014;16:1322-6.

34. Lobo TJ, Pachon CT, Pachon JC, et al. Atrial fibrillation ablation in systolic dysfunction: clinical and echocardiographic outcomes. Systolic dysfunction: Clinical and
Arq Bras Cardiol. 2015;104:45-52.

35. Bunch TJ, May HT, Bair TL, et al. Five-year outcomes of catheter ablation in patients with atrial fibrillation and left ventricular systolic dysfunction. J Cardiovasc Electrophysiol. 2015;26:363-70

36. Rillig A, Makimoto H, Wegner J, et al. Six-year clinical outcomes after catheter ablation of atrial fibrillation in patients with impaired left ventricular function. I Cardiovasc Electrophysiol. 2015;26:1169-79.

37. Kato K, Ejima K, Fukushima N, et al. Catheter ablation of atria fibrillation in patients with severely impaired left ventricular systolic function. Heart Vessels. 2016;31:584-92.

38. Yanagisawa $\mathrm{S}$, Inden $\mathrm{Y}$, Kato $\mathrm{H}$, et al. Decrease in B-type natriuretic peptide levels and successful catheter ablation for atrial fibrillation in patients with heart failure. Pacing Clin Electrophysiol. 2016:39:225-34.

39. Ullah W, Ling LH, Prabhu S, et al. Catheter ablation of atrial fibrillation in patients with heart failure: impact of maintaining sinus rhythm on heart failure status and long-term rates of
sibrilation in patients with heart failure: Impact of maintaining sinus rhythm on heart failure status and long-
stroke and death. Europace. 2016;18:679-86.

0. Khan MN, Jaïs P, Cummings J, et al. Pulmonary-vein isolation for atrial fibrillation in patients with heart failure. $N$ Eng/ I Med. 2008;359:1778-85.

41. MacDonald MR, Connelly DT, Hawkins NM, et al. Radiofrequency ablation for persistent atrial fibrillation in patients with advanced heart failure and severe left ventricular systolic dysfunction: A randomised controlled trial. Heart. 2011:97:740-7.

42. Jones DG, Haldar SK, Hussain W, et al. A randomized tria to assess catheter ablation versus rate control in the management of persistent atrial fibrillation in heart failure. $J$ Am Coll Cardiol. 2013;61:1894-903.

43. Hunter RJ, Berriman TJ, Diab I, et al. A randomized controlled trial of Catheter Ablation Versus Medical Treatment of Atrial Fibrillation in Heart Failure (The CAMTAF Trial). Circ Arrhythm Electrophysiol. 2014;7:31-8.

44. Di Biase L, Mohanty P, Mohanty S, et al. Ablation versus amiodarone for treatment of persistent atrial fibrillation in patients with congestive heart failure and an implanted device. Results from the AATAC multicenter randomized trial. Circulation. 2016;133:1637-44.

45. Prabhu S, Taylor AJ, Costello BT, et al. Catheter ablation versus medical rate control in atrial fibrillation and systolic dysfunction. The CAMERA-MRI study. J Am Coll Cardiol. 2017:70:1949-61.

46. Marrouche NF, Brachmann J, Andresen D, et al. Catheter ablation for atrial fibrillation with heart failure. N Eng/ I Med. 2018:378:417-27.

47. AlTurki A, Proietti R, Dawas A, et al. Catheter ablation for atria fibrillation in heart failure with reduced ejection fraction: a systematic review and meta-analysis if randomized controlled trials. Cardiovasc Disord. 2019;19:18-30

48. Turagam MK, Garg J, Whang W, et al. Catheter ablation of atria fibrillation in patients with heart failure. A meta-analysis of randomized controlled trials. Ann Intern Med. 2019;170:41-50.

49. Ruzieh M, Foy AJ, Aboujamous NM, et al. Meta-analysis of atrial fibrillation ablation in patients with systolic heart failure. Cardiovasc Ther. 2019: DOl: 10.1155/2019/8181657.

50. Elgendy AY, Mahmoud AN, Khan MS, et al. Meta-analysis comparing catheter-guided ablation versus conventional medical therapy for patients with atrial fibrillation and heart failure with reduced ejection fraction. $\mathrm{Am} \mathrm{I}$ Cadiol. 2018;122:806-13.

51. Smer A, Salih M, Darrat $Y H$, et al. Meta-analysis of randomized controlled trials on atrial fibrillation in patients with heart failure with reduced ejection fraction. Clin Cardiol. 2018;41:1430-8.

52. Briceño DF, Markman TM, Lupercio F, et al. Catheter ablation versus conventional treatment of atrial fibrillation in patien with heart failure with reduced ejection fraction: a systematic review and meta-analysis of randomized controlled trials. Jinterv Card Electrophysiol. 2018:53:19-29.
53. Ma Y, Bai F, Qin F, et al. Catheter ablation for treatment of patients with atrial fibrillation in heart failure: a meta-analysis of randomized controlled trials. Cardiovasc Disord. 2018:18:165-72.

54. Machino-Ohtsuka T, Seo Y, Ishizu T, et al. Efficacy, safety, and outcomes of catheter ablation of atrial fibrillation in patients outcomes of catheter ablation of atrial fibrillation in patients
with heart failure with preserved ejection fraction. J Am Coll with heart failure with preser
Cardiol. 2013;62:1857-65.

55. Black-Maier E, Ren X, Steinberg BA, et al. Catheter ablation of atrial fibrillation in patients with heart failure and preserved ejection fraction. Heart Rhythm. 2018;15:651-7.

56. Vogler J, Willems S, Sultan A, et al. Pulmonary vein isolation versus defragmentation: The CHASE-AF Clinical Trial. J Am Coll Cardiol. 2015;66:2743-52.

57. Fink T, Schluter M, Heeger $\mathrm{CH}$, et al. Stand-alone pulmonary vein isolation versus pulmonary vein isolation with additional substrate modification as index ablation procedures in patients with persistent and long-standing persistent atrial fibrillation: The pandomized AlsterHospital for Long-Standing Persistent Atrial Fibrillation). Circ Hospital for Long-Standing Persistent Atrial
Arrhythm Electrophysiol. 2017:10:e005114.

58. Santhanakrishnan R, Wang N, et al. Atrial fibrillation begets heart failure and vice versa; temporal associations and differences in preserved versus reduced ejection fraction. Circulation. 2016;133:484-92.

59. Siontis $K C$, Yao $X$, Noseworthy PA. Atrial fibrillation in heart failure syndromes: does it matter more in some than in others? Eur Heart J. 2018;39:4285-86.

60. Roy D, Talajic M, Nattel S, et al. Rhythm control versus rate control for atrial fibrillation and heart failure. N Eng/ I Med. 2008;358:2667-77.

61. Ponikowski P, Voors AA, Anker SD, et al. 2016 ESC Guidelines for the diagnosis and treatment of acute and chronic heart failure: the Task Force for the diagnosis and treatment of acute and chronic heart failure of the European Society of Cardiology (ESC). Developed with the special contribution of the Heart Failure Association (HFA) of the ESC. Eur Heart 1 . 2016:37:2129-200

62. Zafrir $B$, Lund $L H$, Laroche $C$, et al. Prognostic implications of atrial fibrillation in heart failure with reduced, mid-range, and preserved ejection fraction: a report from 14964 patients in the European Society of Cardiology Heart Failure Long-Term Registry. Eur Heart J. 2018;39:4277-84.

63. Sartipy U, Dahlstrom U, Fu M, Lund LH. Atrial fibrillation in heart failure with preserved, mid-range, and reduced ejection fraction. JACC Heart Fail. 2017:5:565-74. 